\title{
MANAJEMEN KULTUR SEKOLAH DALAM UPAYA PENINGKATAN MUTU PENDIDIKAN DI SMA NEGERI 2 BREBES
}

\author{
Evi Rovikoh Indah Saputri \\ Program Studi Kebijakan Pendidikan, Universitas Negeri Yogyakarta \\ i.saputri56@uny.ac.id
}

\begin{abstract}
Abstrak
Salah satu upaya yang dilakukan sekolah untuk meningkatkan prestasi siswa adalah mengembangkan kultur sekolah. Artikel ini bertujuan untuk menyajikan manajemen kultur sekolah di SMAN 2 Brebes sebagai upaya peningkatan mutu pendidikan yang meliputi kultur berprestasi, berkarakter, dan kegiatan ekstrakurikuler. Penelitian ini menggunakan pendekatan kualitatif dengan teknik pengumpulan data berupa observasi, wawancara, dan dokumentasi. Hasil penelitian menunjukkan bahwa manajemen kultur sekolah dilakukan dengan mengembangkan kultur berprestasi, berkarakter, dan kegiatan ekstrakurikuler. Kultur Berprestasi dilaksanakan dengan kompetisi akademik, non-akademik, keikutsertaan lomba, pembelajaran efektif. Kultur berkarakter dilaksanakan dengan 18 nilai karakater yang harus dimiliki oleh warga sekolah serta kegiatan pembiasaan. Kegiatan ekstrakurikuler dilaksanakan meliputi kegiatan wajib dan pilihan. Upaya tersebut dilandasi oleh keinginan sekolah untuk berprestasi dalam rangka membangun kepercayaan masyarakat bahwa sekolah mampu mencetak siswa yang berprestasi dan menjadi kebanggaan.
\end{abstract}

Kata kunci: Manajemen, Kultur sekolah, Mutu pendidikan

\begin{abstract}
One of the efforts made by the school to improve student achievement is develop school culture. This article aims to present school culture management at SMAN 2 Brebes as an effort to improve the quality of education which includes achievement culture, character, and extracurricular activities. This study uses a qualitative approach in which observation, interviews, and documentation used as data collection techniques. The results showed that school culture management was carried out by developing achievement culture, character, and extracurricular activities. Achievement culture is carried out through academic and non-academic competitions, competition participation, and effective learning. Characteristic culture is performed with 18 character values that must be owned by the school community as well as habituation activities. Extracurricular activities carried out include compulsory and optional activities. These efforts are based on the school desire for build public trust that the school is able to produce outstanding students and become pride.
\end{abstract}

Keywords: Management, School Culture, Quality of education 


\section{PENDAHULUAN}

Sekolah sebagai suatu sistem memiliki tiga aspek pokok yang sangat berkaitan erat dengan mutu sekolah, yakni: proses belajar mengajar, kepemimpinan dan manajemen sekolah, serta kultur sekolah. Program aksi untuk peningkatan mutu sekolah secara konvensional senantiasa menekankan pada aspek pertama, yakni meningkatkan mutu proses belajar mengajar, sedikit menyentuh aspek kepemimpinan dan manajemen sekolah, dan sama sekali tidak pernah menyentuh aspek kultur sekolah. Pilihan tersebut tidak salah, karena aspek itulah yang paling dekat dengan prestasi siswa.

Peningkatan mutu pendidikan pada semua jenjang termasuk Sekolah Menengah Atas (SMA) memerlukan langkah-langkah dan tindakan nyata di tingkat sekolah, kelas, dan masyarakat lokal tempat sekolah beroperasi. Ada dua strategi yang berfokus pada dimensi struktural dan kultural dengan tekanan pada perilaku nyata dalam bentuk tindakan.

Perbaikan sistem sekolah pada intinya adalah membangun kultur sekolah sebagai kekuatan utama sekolah yang bersangkutan. Perbaikan mutu sekolah perlu memahami kultur sekolah. Dengan pemahaman kultur sekolah, maka berfungsinya sekolah dapat dipahami, aneka permasalahan dapat diketahui, dan pengalaman-pengalamannya dapat direfleksikan. Dalam menciptakan iklim dan kultur sekolah yang kondusif diperlukan manajemen.

SMA Negeri 2 Brebes mengembangkan kultur sekolah berprestasi, kultur berkarakter, dan kegiatan ekstrakurikuler. Pengembangan kultur tersebut upaya meningkatkan mutu pendidikan. SMA Negeri 2 Brebes memiliki prestasi akademik dan non akademik yang bagus. Prestasi bidang akademik dilihat dari presentase kelulusan dan peringkat sekolah di kabupaten berdasarkan hasil ujian nasional, sedangkan prestasi non akademik dilihat dari berbagai kejuaraan pada bidang seni, kreasi, dan olahraga. Dalam rangka melaksanakan pengembangan kultur di sekolah yang perlu diperhatikan oleh sekolah adalah tahapan manajemen. Namun demikian dalam proses tahapan manajemen perlu adanya kejelasan tentang semua rangkaian kegiatan 
manajemen kultur sekolah yang meliputi perencanaan, pengorganisasian, pengarahan, dan pengawasan itu, serta perlu adanya alasan terbuka terkait perkembangan kultur sekolah yang dikembangkan. Berdasarkan alasan itulah penelitian Manajemen Kultur Sekolah dalam Upaya Peningkatan Mutu Pendidikan di SMA 2 Brebes dilaksanakan. Penelitian ini ingin melihat bagaimana tahapan manajemen mulai dari alasan pemilihan pengembangan kultur, perencanaan, pengorganisasian, pelaksanaan, pengawasan, serta indikator keberhasilan pengembangan kultur sekolah dalam upaya peningkatan mutu pendidikan di SMA Negeri 2 Brebes.

Rendahnya mutu pendidikan SMA merupakan salah satu persoalan besar yang dihadapi dunia pendidikan nasional. Kata kunci untuk menggambarkan sistem pendidikan nasional yang mampu menjawab berbagai tantangan arus globalisasi di masa mendatang tiada lain adalah pendidikan yang bermutu. Secara umum, mutu (quallty) adalah gambaran dan karakteristik menyeluruh dari barang atau jasa yang menunjukkan kemampuannya dalam memuaskan kebutuhan yang diharapkan atau yang tersirat. Mutu merupakan suatu istilah yang dinamis dan terus bergerak, jika bergerak maju dikatakan mutunya bertambah baik, sebaliknya jika bergerak mundur dikatakan mutunya menurun (Depdiknas, 2001: 25).

Sesuatu dikatakan bermutu jika terdapat kecocokan antara syarat-syarat yang dimiliki oleh benda yang dikehendaki dengan maksud dari orang yang menghendakinya (Matsuhu, 2004: 65). "The ftness purpose as precieved by the customer". Misalnya, mutu proses belajar mengajar dianggap cocok sesuai harapan peserta didik; semakin melesat melampaui dari apa yang diharapkan peserta didik, berarti semakin bermutu proses belajar mengajarnya, jika terjadi sebaliknya, berarti semakin tidak bermutu (Idrus dkk, 2000: 2).

Peningkatan mutu pendidikan perlu adanya manajemen sekolah yang terstruktur, dan melewati tahapan proses. Manajemen adalah suatu proses yang berbeda terdiri dari planning, organizing, actuating dan controling yang dilakukan untuk mencapai tujuan yang ditentukan dengan menggunakan manusia dan sumber daya lainnya (Yayat M. Herujito, 2001: 3). Dengan kata 
lain, berbagai jenis kegiatan yang berbeda itulah yang membentuk manajemen sebagai suatu proses yang tidak dapat dipisah-pisahkan dan sangat erat hubungannya. Manajemen dipandang sebagai ilmu karena manajemen merupakan pengetahuan yang tersusun secara sistematis dalam memahami mengapa dan bagaimana orang bekerja dalam mencapai tujuan (Syarifudin, 2011:2).

Fungsi-fungsi manajemen adalah sebagai berikut:

a. Planning deciding what objectives to pursue during a future period and what to do achieve those objectives

b. Organizing grouping activities, assigning activities, and providing the authority necessary to carry out the activities

c. Staffing determining human resource needs and recruiting, selecting training, and developing human resources

d. Leading, diresting and chaneling human behaviour toward the accomplishment of objectives

e. Controlling, measuring performance against objectives, determining the causes of deviations, and taking corrective action where necessary (Rue\&Byars, 2000: 6).

Dalam proses tahapan manajemen kaitannya dengan peningkatan mutu pendidikan di SMA Negeri 2 Brebes perlu adanya kejelasan tentang semua rangkaian kegiatan manajemen kultur sekolah yang meliputi perencanaan, pengorganisasian, pengarahan, dan pengawasan tersebut.

Manajemen iklim dan kultur sekolah mempunyai arti yang sangat luas, tidak terbatas pada masalah manajemen saja. Dalam hal ini sekolah diharapkan mampu menciptakan iklim yang kondusif bagi perkembangan pribadi peserta didik, tidak menjadi lembaga mekanik, birokratik, dan kaku, tetapi menjadi sebuah lembaga sosial yang organik, demokratik, dan inovatif (Mulyasa, 2011: 103).

Stolp dan Smith membagi tiga lapisan kultur yaitu artifak di permukaan, nilai-nilai keyakinan di tengah, dan asumsi di dasar. Artifak adalah lapisan kultur sekolah yang segera dan paling mudah diamati seperti aneka hal ritual 
sehari-hari di sekolah, berbagai upacara, benda-benda simbolik di sekolah, dan aneka ragam kebiasaan yang berlangsung di sekolah. Lapisan kultur sekolah yang lebih dalam berupa nilai-nilai dan keyakinan-keyakinan yang ada di sekolah. Ini menjadi ciri utama suatu sekolah. Sebagian berupa norma-norma perilaku yang diinginkan sekolah. Lapisan paling dalam kultur sekolah adalah asumsi-asumsi yaitu simbol-simbol, nilai-nilai dan keyakinan-keyakinan yang tidak dapat dikenali tetapi terus menerus berdampak terhadap perilaku warga sekolah (Depdiknas, 2003: 8-10).

Kultur sekolah adalah seperangkat keyakinan, nilai, norma, perilaku, tradisi atau kebiasaan, dan simbol yang dihasilkan dari persepsi individu dan kolektif yang ada di sekolah yang menghasilkan kebiasaan perilaku warga sekolah. Manajemen kultur sekolah dapat diartikan sebagai suatu proses perencanaan, pengorganisasian, penggerakkan, pengawasan yang dilaksanakan secara sistematis, efektif, dan efisien tentang kebiasaan perilaku warga sekolah untuk mencapai tujuan tertentu yang telah ditetapkan sekolah.

Kepala sekolah sebagai sentral pengembangan kultur sekolah harus dapat mejadi contoh dalam berinteraksi di sekolah. Ia adalah figur yang memiliki komitmen terhadap tugas sekolah, jujur dalam kata dan perbuatan, dan selalu bermusyawarah dalam membuat kebijakan sekolah, ramah, dan menghargai pendapat orang lain. Selain itu, kepala sekolah merupakan model bagi warga sekolah (Depdiknas, Direktorat Pendidikan Menengah Umum, 2003: 11).

\section{METODE}

Pendekatan penelitian ini menggunakan metode kualitatif. Penelitian ini dilaksanakan di SMA Negeri 2 Brebes dengan pertimbangan sekolah tersebut merupakan sekolah unggulan di kabupaten brebes yang sebelumnya memiliki program rintisan sekolah bertaraf internasional. Penelitian ini bertujuan untuk menggali semua informasi manajemen kultur sekolah dalam upaya peningkatan mutu pendidikan yang meliputi kultur berprestasi, berkarakter, dan kegiatan ekstrakurikuler di SMA Negeri 2 Brebes ditinjau dari aspek 
pemilihan dan pengembangan kultur sekolah, keyakinan dan asumsi kultur sekolah, tujuan dikembangkannya kultur sekolah, perencanaan, pengorganisasian, pelaksanaan, pengawasan, keberhasilan kultur sekolah. Pengumpulan data penelitian ini menggunakan observasi, wawancara mendalam, dan dokumen. Keabsahan data dilaksanakan untuk menguji kredibilitas, menggunakan triangulasi data, membercheck, dan mengabungkan berbagai teknik pengumpulan data yang digabungkan.

\section{HASIL DAN PEMBAHASAN}

\section{Pemilihan dan Pengembangan Kultur Sekolah}

Dalam upaya peningkatan mutu pendidikan dan mempertahankan sekolah unggulan di SMA Kabupaten Brebes, SMA Negeri 2 Brebes mengembangkan kultur sesuai dengan kondisi sekolah. Kultur yang dikembangkan antara lain kultur berprestasi, kultur berkarakter, dan kegiatan ekstrakurikuler.

\section{a. Alasan Dikembangkan Kultur Sekolah}

Alasan dikembangkan kultur sekolah karena adanya potensi yang bisa mendukung dikembangkannya kultur sekolah yaitu potensi siswa dilihat dari prestasinya baik akademik dan non-akademik, potensi guru dilihat dari tingginya komitmen guru untuk melaksanakan tugas dan menyesuaikan dengan tuntutan tugas dan tanggung jawabnya, dan potensi sarana prasarana dilihat dari pemenuhan perangkat komputer untuk pembelajaran dan seluruh ruang kelas sudah terpasang LCD untuk pembelajaran

\section{b. Keyakinan dan Asumsi Kultur Sekolah}

Sekolah memiliki asumsi bahwasanya pelaksanaan kultur berprestasi dan kegiatan ekstrakurikuler harus dilandasi dengan karakter positif. Diharapkan dari pelaksanaan kegiatan prestasi, karakter dan kegiatan ekstrakurikuker diyakini dapat menunjukkan adanya keinginan untuk memajukan sekolah. 


\section{c. Tujuan Dikembangkannya Kultur Sekolah}

Tujuan pengembangan kultur berprestasi, berkarakter, dan kegiatan ekstrakurikuler adalah mewujudkan visi dan misi sekolah, dan diharapkan warga sekolah berperan dalam pengembangan kultur tersebut dalam rangka mewujudkan dan meningkatkan kualitas pendidikan khususnya kualitas SMA 2 Brebes.

\section{Manajemen Pengembangan Kultur Sekolah}

Tahap ini akan dibahas bagaimana perencanaan, pengorganisasian, penggerakkan atau pelaksanaan, serta pengawasan pengembangan kultur sekolah yang ada di SMA Negeri 2 Brebes.

\section{a. Perencanaan}

Perencanaan yang dilakukan sekolah dalam mengembangkan kultur berprestasi adalah dengan kerja sama dengan berbagai pihak, baik guru, siswa, kepala sekolah dan luar sekolah seperti perguruan tinggi dan lembaga. Bentuk kerjasama dengan perguruan tinggi adalah dengan mengirimkan siswa yang akan ikut olimpiade ke perguruan tinggi tersebut untuk mengikuti proses karantina. Dalam melakukan perencanaan pengembangan kultur sekolah, SMA Negeri 2 Brebes menyesuaikan dengan program-program yang sudah ditetapkan sebelumnya seperti tujuan pendidikan, perencanaan program kesiswaan, sarana prasarana.

\section{b. Pengorganisasian}

Dalam pengorganisasian kepala sekolah hanya menambahkan kewenangan, tanggung jawab, dan tugas kepada pengelola sekolah yaitu wakil kepala sekolah tertentu untuk mengembangkan kultur sekolah. Untuk kultur prestasi dimana kegiatannya mengorganisir kegiatan pembelajaran serta menangani prestasi-prestasi akademik, kepala sekolah memberikan kewenangan, tanggung jawab, dan tugas kepada wakil kepala sekolah urusan kurikulum. Sedangkan wakil 
kepala sekolah urusan kesiswaan untuk prestasi-prestasi non-akademik dan urusan kegiatan ekstrakurikuler. Untuk kultur karakter kepala sekolah memberikan kewenangan, tanggung jawab, dan tugas kepada wakil kepala sekolah urusan humas dan seluruh warga sekolah.

\section{c. Pelaksanaan}

Strategi yang ditempuh sekolah untuk kultur berprestasi adalah dengan memberikan muatan kurikulum berupa pemantapan materi di sore hari, serta menambah muatan teknologi dengan memberikan fasilitas komputer. Landasan kultur berprestasi adalah dengan sekolah memiliki banyak prestasi akademik, dan nonakademik. Kultur prestasi akademik dilaksanakan dengan kompetisi akademik, dan pembelajaran efektif. Kultur prestasi non-akademik dilakukan melalui kompetisi non-akademik, keikutsertaan siswa dalam penyelenggaraan berbagai lomba yang tidak berkaitan langsung dengan pembelajaran di kelas.

Dalam mengembangkan kultur berkarakter di sekolah, SMA 2 Brebes mengembangkan delapan belas nilai karakter yang harus dimilki oleh warga sekolah diantaranya: (1) religius, (2) jujur, (3) toleransi, (4) disiplin, (5) kerja keras, (6) kreatif, (7) mandiri, (8) demokratis, (9) rasa ingin tahu, (10) rasa kebanggaan, (11) cinta tanah air, (12) menghargai prestasi, (13) bersahabat/komunikatif, (14) cinta damai, (15) gemar membaca, (16) peduli lingkungan, (17) peduli sosial, (18) tanggung jawab. Kegiatan pembiasaan yang meliputi kegiatan bersifat pembinaan karakter peserta didik yang dilakukan secara rutin, spontan, dan keteladanan diterapkan oleh warga sekolah guna mendukung pengembangan kultur berkarakter.

Pemilihan jenis kegiatan ekstrakurikuler di SMA Negeri 2 Brebes menyesuaikan dengan kebutuhan dan minat siswa di sekolah. Untuk mendapatkan kesesuaian antara minat siswa dengan penyelenggaraan ekstrakurikuler, pemilihan ekstrakurikuler dilaksanakan dengan sosialisasi saat Masa Orientasi Sekolah (MOS), 
informasi kegiatan ekstrakurikuler sekolah beserta waktu kegiatannya dan pembina kegiatan yang dipasang di majalah dinding sekolah yang kemudian siswa diberikan angket peminatan kegiatan yang akan diikuti oleh siswa. Kegiatan ekstrakurikuler dilaksanakan di luar kegiatan tatap muka atau sore hari. Kegiatan ekstrakurikuler meliputi kegiatan wajib dan pilihan.

\section{d. Pengawasan}

Pengawasan pelaksanaan dilakukan oleh warga SMA Negeri 2 Brebes sendiri yang meliputi kepala sekolah, wakil kepala sekolah, guru, karyawan, dan para siswa baik dengan komunikasi resmi melalui forum rapat, sosialisasi, atau dengan komunikasi tidak resmi, dengan pengamatan terhadap sikap dan perilaku siswa, serta melalui prestasi yang diraih sekolah.

\section{Keberhasilan Kultur Sekolah}

Keberhasilan pelaksanaan kultur sekolah dapat dilihat dari berbagai indikator. Karena menyangkut manajemen maka yang pertama adalah dilihat dari perencanaannya, kedua pelaksanaannya, ketiga sukses dalam hal laporan, dan yang keempat adalah sukses dalam hasil. Untuk hasil yang sudah di dapat sekolah dan termasuk dalam indikator keberhasilan kultur sekolah adalah prestasi sekolah, serta kepercayaan dinas, kabupaten, dan masyarakat terhadap SMA Negeri 2 Brebes menjadi bertambah. Dalam pelaksanaannya terdapat empat kendala. Yang pertama sekolah dan guru masih sulit untuk menyatukan dan memfokuskan salah satu dari kegiatan-kegiatan utama dalam hal mengajar dengan kegiatan-kegiatan tambahan seorang guru. Yang kedua, siswa masih belum bisa mengatur waktu antara tugas utama siswa di sekolah dengan kegiatan-kegiatan lain yang diikuti siswa di sekolah. Yang ketiga, semangat guru dalam hal mengajar. Yang keempat adalah pembiayaan. 


\section{Memotivasi Warga Sekolah}

Memotivasi merupakan hal penting dalam pelaksanaan kultur sekolah. Untuk memotivasi warga sekolah tentang pengembangan kultur sekolah, telah dilaksanakan banyak cara. Langkah yang telah dilakukan sekolah adalah dengan menanamkan keyakinan, keteladanan, pembiasaan, dan melalui forum upacara dan rapat. Keteladanan guru-guru dan kepala sekolah juga merupakan bentuk motivasi pengembangan kultur sekolah. Guru-guru menanamkan karakter ke siswa lewat dirinya bagaimana bisa menjadi model yang baik bagi siswa.

\section{SIMPULAN}

Berdasarkan analisis dan pembahasan hasil penelitian dapat disimpulkan bahwa SMA Negeri 2 Brebes dalam upaya peningkatan mutu pendidikan telah mengembangkan kultur berprestasi, berkarakter, dan kegiatan ekstrakurikuler. Pengembangan kultur sekolah dalam upaya peningkatan mutu pendidikan di SMA Negeri 2 Brebes, sekolah memeperhatikan proses yaitu dengan sekolah sudah melaksanakan keempat fungsi manajemen yaitu perencanaan, pengorganisasian, pelaksanaan, dan pengawasan. Keberhasilan pengembangan kultur sekolah juga menunjukkan peningkatan mutu pendidikan, terlihat dengan peningkatan prestasi baik akademik atau non-akademik dari tahun ke tahun, kepercayaan masyarakat bertambah dengan banyaknya siswa mendaftar sebagai calon peserta didik SMA Negeri 2 Brebes, serta karakter positif yang dimiliki warga sekolah khususnya siswa. Penegembangan kutlur sekolah dalam upaya mingkatkan mutu perlu adanya motivasi dari sekolah. Langkah yang telah dilakukan sekolah adalah dengan menanamkan keyakinan, keteladanan, pembiasaan, dan melalui forum upacara dan rapat. Keteladanan guru-guru dan kepala sekolah juga merupakan bentuk motivasi pengembangan kultur sekolah. Guru-guru menanamkan karakter ke siswa lewat dirinya bagaimana bisa menjadi model yang baik bagi siswa. 
Dalam penelitian yang saya lakukan berkaitan dengan manajemen kultur sekolah dalam upaya peningkatan mutu pendidikan di SMA Negeri 2 Brebes, terdapat 2 saran sebagai berikut:

1. Diharapkan sekolah mulai mendokumentasikan secara tertulis seluruh aspek manajemen kultur sekolah yang meliputi perencanaan, pengorganisasian, penggerakkan atau pelaksanaan, dan pengawasan.

2. Kultur sekolah yang dilaksanakan di SMA Negeri 2 Brebes yang meliputi kultur berprestasi, kultur berkarakter, dan kultur kegiatan ekstrakurikuler merupakan kultur positif yang kiranya dapat menjadi sumber inspirasi sekolah lain untuk melaksanakan dengan disesuaikan kondisi sekolah masing-masing.

\section{DAFTAR PUSTAKA}

Depdiknas. (2001). Manajemen Peningkatan Mutu Berbasis Sekolah. Jakarta: Direktorat Jenderal Pendidikan Dasar dan Menengah.

Direktorat Pendidikan Menengah Umum, Depdiknas. (2003). Pedoman Pengembangan Kutur Sekolah. Jakarta: Dit. Dikmenum.

Herujito, Yayat M. (2001). Dasar-Dasar Manajemen. Jakarta: Grasindo.

Hikmat. (2009). Manajemen Pendidikan. Bandung: Pustaka Setia

Idrus, dkk. (2002). Quality Assurance. Handbook, 3Edition, Engineering Education Development Project, DU Malcomlm Jones 9ed). Jakarta: Directoral General of Higher Education

Matsuhu. (2004). Menata Ulang Pemikiran Sistem Pendidikan Nasional dalam Abad 21. Yogyakarta: Safiria Insani Press

Mulyasa. (2011). Manajemen \& Kepemimpinan Kepala Sekolah. Jakarta: Bumi Aksara

Rue, W.L \& Byars. L.L. (2000). Management skill and application. Eight Edition. New York: Irwin McGraw-Hill

Syarifudin. (2011). Manajemen Pendidikan. Jakarta: Diadit Media

------------. (2004). Pedoman Pengembangan Kultur Sekolah. jakarta: Direktorat pendidikan Menengah Umum. 